\title{
Health literacy and functional exercise adherence in postoperative breast cancer patients
}

\author{
This article was published in the following Dove Press journal: \\ Patient Preference and Adherence \\ 13 April 2017 \\ Number of times this article has been viewed
}

\author{
Weiwei Tang ${ }^{1, *}$ \\ Zhouxiao $\mathrm{Li}^{1, *}$ \\ Chongyin Tangl,* \\ Xiaowei Wang ${ }^{2}$ \\ Hanjin Wang' \\ 'Department of General Surgery, \\ Nanjing First Hospital, Nanjing \\ Medical University, Nanjing, \\ Jiangsu, People's Republic of China; \\ ${ }^{2}$ Department of Medical Oncology, \\ Huai'an First People's Hospital, \\ Nanjing Medical University, Huai'an, \\ Jiangsu, People's Republic of China \\ *These authors contributed equally to \\ this work
}

Correspondence: Hanjin Wang Department of General Surgery, Nanjing First Hospital, Nanjing Medical University, Changle Road 68, Nanjing, Jiangsu, People's Republic of China Emailwhj_888@sohu.com

Xiaowei Wang

Department of Medical Oncology, Huai'an First People's Hospital, Nanjing

Medical University, Huai'an, Jiangsu,

People's Republic of China

Tel +86 2552887042

Fax +862552269924

Email wxw7352@sina.com
Purpose: To improve the quality of life of patients who received modified radical mastectomy, we investigated the factors affecting health literacy (HL) and exercise adherence in postoperative breast cancer patients and analyzed the relationship between them.

Methods: With random sampling method, we selected patients who received modified radical mastectomy in Nanjing First Hospital as research subjects. Then, questionnaires were given to 286 breast cancer patients who met the inclusion criteria (from January 2014 to June 2016). The questionnaire includes three parts: General Information, the Health Literacy Scale, and the Postoperative Functional Exercise Compliance Scale for Breast Cancer Patients. In this study, the count data were presented as frequency and constituent ratio and the measurement data were presented as mean \pm standard error. Correlation and logistic analysis were both performed by using SPSS for Windows v.19.0.

Results: This study showed that the total mean score of postoperative functional exercise compliance of breast cancer patients was $82.65 \pm 12.38$ points, and the total mean score of postoperative functional exercise compliance of breast cancer patients was $46.16 \pm 3.88$ points. In addition, HL had a strong association with functional exercise compliance in each dimension except for economic support and proactively seeking advice compliance.

Conclusion: HL and functional exercise compliance of breast cancer after radical mastectomy in Nanjing First Hospital were both at a moderate level and need further improvement. HL could predict the functional exercise compliance of patients.

Keywords: postoperative, modified radical mastectomy, patient, health literacy, exercise adherence

\section{Introduction}

Breast cancer, with approximately 1.7 million women diagnosed and treated worldwide annually, imposes a burden both to families and society. ${ }^{1,2}$ Surgery has always played a central role in the management of breast cancer, and radical mastectomy is now becoming the first choice in vast majority of patients. ${ }^{3}$ However, breast cancer patients have to face a series of postoperative complications, including arm pain, edema, dysfunction, and other issues, which has a significant negative impact on their quality of life. ${ }^{4}$

Studies have reported that early postoperative functional exercise is safe and beneficial for breast cancer survivors and helps to reduce the ipsilateral upper extremity flap adhesions, limb edema, joint stiffness, and muscle atrophy and also improves the function of limb. ${ }^{5}$ However, long-term adherence to exercise programs is not easy to accomplish.

In 1974, Simonds, the American scholar, put forward the concept of health literacy (HL) in the international conference for the first time. ${ }^{6}$ Then, the World Health 
Organization defined HL as the individual's cognitive and social skills, determining the individual's understanding and use of motivation and ability to maintain and promote health information. ${ }^{?}$

Numerous reports have showed that HL could affect cancer patients' understanding of therapeutic goals and treatment compliance. Husson et $\mathrm{al}^{8}$ explored the relationship between HL and health-related quality of life and found that low subjective functional HL among colorectal cancer survivors was associated with lower levels of physical activity and poorer health-related quality of life. Rust et $\mathrm{al}^{9}$ studied the relationship between initial HL and medication adherence, as well as initial HL and self-efficacy, and the results indicated that individuals with higher HL were more likely to have higher levels of self-efficacy and were more likely to adhere to medication instructions. Jin et $\mathrm{al}^{10}$ conducted a cross-sectional survey to examine the functional HL among older adults and identify influencing factors that can predict medication adherence. A total of 160 participants aged $\geq 65$ years were enrolled. The results showed that medication adherence of elderly patients was linked to education level, health-related problems, dosing frequency, satisfaction with patient counseling, and explanation of medication, but it was not associated with functional HL. As a result, pharmacists should take elderly patients' individual characteristics such as educational background and specific patient-related health problems into consideration so as to provide sufficient information and explanation of medication and ensure patient satisfaction with the counseling.

In China, survey of cancer patients with HL research is rare and remains to be explored. As a result, this research investigated the factors affecting the health literacy and exercise adherence in postoperative breast cancer patients and analyzed the relationship between them.

\section{Research patients and methods Study design and participants}

Three hundred ten patients who received modified radical mastectomy in Nanjing First Hospital from January 2014 to June 2016 were selected in this survey. Data were collected from 295 patients on-site, and the recovery rate was $95.2 \%$. Removing the incomplete questionnaires and those with logical errors, a total of 286 valid questionnaires were collected finally and included in this study.

The inclusion criteria were as follows:

1. Each breast cancer patient having received modified radical mastectomy

2. Patients knowing the diagnosis of the disease
3. Patients having the ability to read and write and fill in the questionnaire independently

The exclusion criteria were as follows:

1. Pathology diagnosis being made outside Nanjing First Hospital

2. Patients with unsuccessful investigation

Written informed consent was obtained from all patients prior to participation in the study. The medical ethics committee of Nanjing First Hospital, Nanjing Medical University, approved the study.

\section{Research methods}

The survey data were collected by using a questionnaire that consisted of three parts: the General Information, the Health Literacy Management Scale, and the Postoperative Functional Exercise Compliance Scale for Breast Cancer Patients. Figure 1 shows the flowchart of the research methods.

\section{General Information questionnaire}

The questionnaire investigated the general information of patients who underwent modified radical mastectomy for breast cancer, and these data included gender, age, marital status, occupational, education, types of Medicare, place of residence, and monthly allowance.

\section{Health Literacy Management Scale}

The scale consisted of 24 items with a total of 120 points, all of which were scored using five-point scale $(5=$ no difficulty, $4=$ little difficulty, $3=$ some difficulties; $2=$ particularly difficult; $1=$ almost impossible to accomplish). The higher the score got, the higher the level of HL was. The scale is divided into four dimensions: information acquisition ability (9 items), communication and interaction ability (9 items), willingness to improve health (4 items), and economic support will ( 2 items).

\section{Postoperative Functional Exercise Compliance Scale for Breast Cancer Patients}

This scale consists of 18 entries with scores ranging from 18 to 72 (4= have no any difficulty to accomplish; $3=$ almost accomplish, $2=$ occasionally accomplish, $1=$ simply not able to accomplish). The scale was divided into three dimensions: physical exercise compliance (9 items), postoperative attention compliance (5 items), and active seeking for compliance (4 items).

\section{Statistical method}

The count data were presented as frequency and constituent ratio, and the measurement data were presented as 


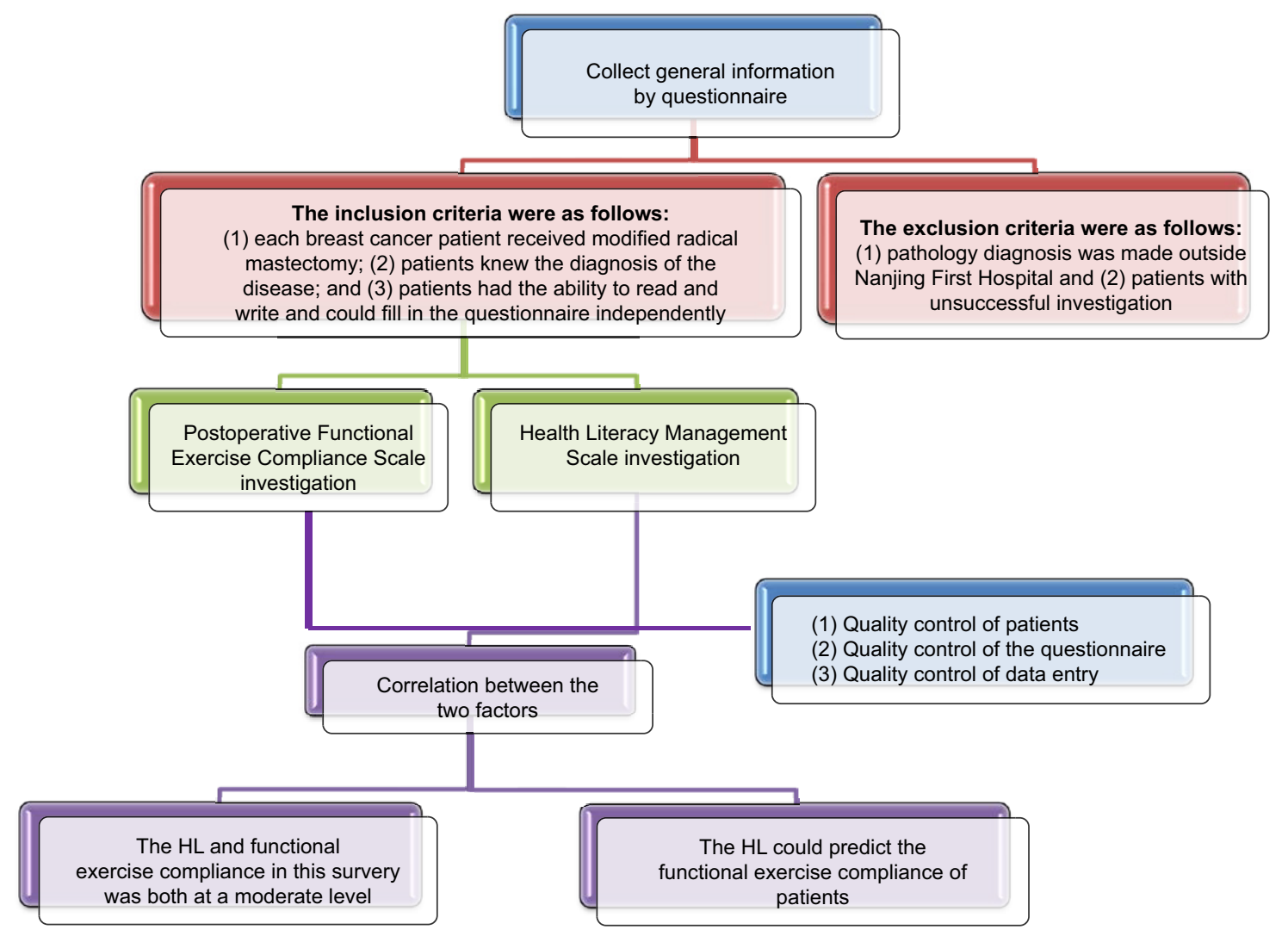

Figure I A flowchart of the research methods.

Abbreviation: $\mathrm{HL}$, health literacy.

mean \pm standard error. Correlation and logistic analysis were performed both by using SPSS for Windows v.19.0 (SPSS, Chicago, IL, USA). For all statistical tests, $P<0.05$ was defined as statistically significant.

\section{Quality control \\ Quality control of patients}

The purpose of the study and each part of the questionnaire were explained to the patients before filling of the questionnaire. Each questionnaire was completed alone by the patients, and then the investigators checked them and asked the patients to take time to fill the blank.

\section{Quality control of the questionnaire}

Before the data entry, the collected questionnaires were sorted out and selected, and the unqualified questionnaires were removed.

\section{Quality control of data entry}

The completeness of all questionnaires was checked before data entry by using the double-entry method. Significant deletions of data as well as logistic errors were corrected by searching the original questionnaire.

\section{Results}

A total of 310 questionnaires were sent out during the survey, 295 were collected on-site, and so the recovery rate was $95.2 \%$. Removing the incomplete questionnaires and those with logical error, a total of 286 valid questionnaires were collected finally, making the effective recovery rate $92.3 \%$.

\section{The general information of postoperative breast cancer patients}

The frequency and ratio was used to describe the sociological data of patients. Gender, age, marital status, occupation, education, types of Medicare, place of residence, and monthly allowance were investigated and are presented in Table 1.

\section{The status of $\mathrm{HL}$ of breast cancer patients after radical mastectomy}

The total scores of HL and the scores of each dimension of patients after radical mastectomy are shown in Table 2 . The mean scores for each group were $32.28,28.43,14.94$, and 7.00 , respectively, and the total mean score of HL of breast cancer patients was $82.65 \pm 12.38$. 
Table I General information of postoperative breast cancer patients

\begin{tabular}{|c|c|c|}
\hline Variables & $\mathbf{N}$ & $\%$ \\
\hline \multicolumn{3}{|l|}{ Gender } \\
\hline Male & 2 & 0.7 \\
\hline Female & 284 & 99.3 \\
\hline \multicolumn{3}{|l|}{ Age (years) } \\
\hline$<35$ & 67 & 23.4 \\
\hline $35-60$ & 173 & 60.5 \\
\hline$>60$ & 46 & 16.1 \\
\hline \multicolumn{3}{|l|}{ Marital status } \\
\hline Single or never married & 23 & 8.0 \\
\hline Married or cohabitating with someone & 176 & 61.5 \\
\hline Widowed & 35 & 12.2 \\
\hline Divorced or separated & 52 & 18.3 \\
\hline \multicolumn{3}{|l|}{ Occupational workers } \\
\hline Workers & 54 & 18.9 \\
\hline Farmers & 67 & 23.4 \\
\hline Personnel of enterprises and institutions & 56 & 19.6 \\
\hline Civil servants or managers & 27 & 9.4 \\
\hline Self-employed & 31 & 10.8 \\
\hline Freelancers & 25 & 8.8 \\
\hline Other & 26 & 9.1 \\
\hline \multicolumn{3}{|l|}{ Education } \\
\hline Elementary school or less & 33 & 11.5 \\
\hline Middle school & 81 & 28.3 \\
\hline High school & 105 & 36.7 \\
\hline College level or more & 67 & 23.5 \\
\hline \multicolumn{3}{|l|}{ Place of residence } \\
\hline Countryside & 132 & 46.2 \\
\hline Town & 84 & 29.4 \\
\hline City & 70 & 24.4 \\
\hline \multicolumn{3}{|l|}{ Monthly allowance (yuan) } \\
\hline$<1,000$ & 58 & 20.3 \\
\hline $1,000-2,999$ & 88 & 30.8 \\
\hline $3,000-4,999$ & 105 & 36.7 \\
\hline $5,000-9,999$ & 29 & 10.1 \\
\hline $10,000+$ & 6 & 2.1 \\
\hline \multicolumn{3}{|l|}{ Types of Medicare } \\
\hline Insurance for urban employees & 69 & 24.1 \\
\hline Insurance for urban residents & 58 & 20.3 \\
\hline Rural health insurance & 137 & 47.9 \\
\hline Other health insurance & 12 & 4.2 \\
\hline No health insurance & 10 & 3.5 \\
\hline
\end{tabular}

Table 2 The scores of $\mathrm{HL}$ of breast cancer patients after radical mastectomy

\begin{tabular}{lll}
\hline Dimension type & $\begin{array}{l}\text { Score } \\
\text { range }\end{array}$ & $\begin{array}{l}\text { Total score mean } \\
\text { (mean } \pm \text { SE) }\end{array}$ \\
\hline Information acquisition ability & $0-45$ & $32.28 \pm 8.04$ \\
Ability to communicate and interact & $0-45$ & $28.43 \pm 4.67$ \\
Willingness to improve health & $0-20$ & $14.94 \pm 1.77$ \\
Economic support will & $0-10$ & $7.00 \pm 1.63$ \\
Total health literacy score & $0-120$ & $82.65 \pm 12.38$ \\
\hline
\end{tabular}

Abbreviations: HL, health literacy; SE, standard error.
Table 3 The scores of functional exercise compliance of breast cancer patients after radical mastectomy

\begin{tabular}{lll}
\hline Dimension type & $\begin{array}{l}\text { Score } \\
\text { range }\end{array}$ & $\begin{array}{l}\text { Total score mean } \\
(\text { mean } \pm \text { SE) }\end{array}$ \\
\hline Physical exercise compliance & $0-36$ & $18.94 \pm 2.36$ \\
Postoperative attention compliance & $0-20$ & $17.73 \pm 1.90$ \\
$\begin{array}{l}\text { Proactively seek advice compliance } \\
\text { The total score of postoperative }\end{array}$ & $0-16$ & $9.49 \pm 1.43$ \\
$\quad \begin{array}{l}\text { functional exercise compliance } \\
\text { of breast cancer patients }\end{array}$ & & $46.16 \pm 3.88$ \\
\hline
\end{tabular}

Abbreviation: SE, standard error.

\section{Current status of functional exercise compliance after modified radical mastectomy for breast cancer patients}

The total scores of functional exercise compliance and the scores of each dimension in patients with modified radical mastectomy are shown in Table 3. The mean scores for each group were $18.94,17.73$, and 9.49, respectively, and the total mean score of postoperative functional exercise compliance of breast cancer patients was $46.16 \pm 3.88$.

\section{The correlative analysis of patients' HL and functional exercise compliance}

Our result showed that HL had a strong association with functional exercise compliance in each dimension except for economic support will and proactively seeking advice compliance (Table 4). The logistic regression analysis among the total score of postoperative functional exercise compliance of breast cancer patients and factors influencing HL revealed that HL could predict the functional exercise compliance of patients (Table 5).

\section{Discussion}

\section{$\mathrm{HL}$ of breast cancer patients after radical mastectomy}

Information acquisition ability refers to recognizing the health needs and searching for information independently. In this study, the patient's information acquisition ability score was $32.28 \pm 8.0$ points lower than the $41.3 \pm 5.9$ points in patients with chronic diseases. ${ }^{11}$ This may be due by the fact that cancer patients often have multiple complex treatment options and so patients with low levels of HL have limited knowledge of their disease and find it difficult to make informed medical decision. ${ }^{12}$

Communication is the ability of the patient to communicate with others in order to obtain social support to help them. In this study, patients with modified radical mastectomy for breast cancer got $29.06 \pm 7.29$ points on average, which was 
Table 4 The correlative analysis of patients' HL and functional exercise compliance

\begin{tabular}{llllll}
\hline Dimension type & $\begin{array}{l}\text { Information } \\
\text { acquisition } \\
\text { ability }\end{array}$ & $\begin{array}{l}\text { Ability to } \\
\text { communicate } \\
\text { and interact }\end{array}$ & $\begin{array}{l}\text { Improvement } \\
\text { of health will }\end{array}$ & $\begin{array}{l}\text { Economic } \\
\text { support will }\end{array}$ & $\begin{array}{l}\text { Total health } \\
\text { literacy score }\end{array}$ \\
\hline Physical exercise compliance & $0.430^{*}(0.000)$ & $0.148^{*}(0.012)$ & $0.175^{*}(0.000)$ & $0.555^{*}(0.000)$ & $0.433^{*}(0.000)$ \\
Postoperative attention compliance & $0.118^{* *}(0.047)$ & $0.144^{*}(0.015)$ & $0.206^{*}(0.000)$ & $0.245^{*}(0.000)$ & $0.192^{*}(0.000)$ \\
Proactively seek advice compliance & $0.452^{*}(0.000)$ & $0.454^{*}(0.000)$ & $0.402^{*}(0.000)$ & $0.092(0.119)$ & $0.534^{*}(0.000)$ \\
Total score of postoperative & $0.486^{*}(0.000)$ & $0.328^{*}(0.000)$ & $0.355^{*}(0.000)$ & $0.492^{*}(0.000)$ & $0.555^{*}(0.000)$ \\
functional exercise compliance & & & & & \\
\hline
\end{tabular}

Notes: Values within the parentheses represent the $P$-value. $* P<0.01 ; * * P<0.05$.

Abbreviation: $\mathrm{HL}$, health literacy.

not satisfactory. Von Wagner C reported the association between performance on HL measures and health outcomes and found that low HL could affect interactions between patient and medical staff, thereby leading to poor health outcomes. ${ }^{13}$

The willingness to improve health is the degree to which patients voluntarily take the time and effort to improve their health. In this study, the score of patient's willingness to improve health was $14.94 \pm 1.76$ points, indicating that patients' willingness to improve health was strong. Oncologists have also found that patients with high HL are more likely to actively seek out relevant health information. ${ }^{14}$

Economic support will include the patient's willingness to invest in health issues and the ability to pay for medicare by themselves. In this study, the patient's willingness to support their own financial needs was $7.00 \pm 1.63$ points, which was slightly lower. On the one hand, the majority of patients in this survey were from rural areas, and so their economic capacity was limited, and also the rural health insurance has a low proportion of reimbursement. On the other hand, follow-up treatment for breast cancer patients after radical mastectomy is costlier, and so patients had to bear great economic pressure.

HL represents the individual's cognitive skills, social skills, and ability to maintain and promote health information. The results of this study showed that the total mean score of postoperative functional exercise compliance of patients with modified radical mastectomy for breast cancer was $82.65 \pm 12.36$ points lower $(97.2 \pm 12.9$ points) than that of the patients with chronic diseases $(P<0.05){ }^{11}$

\section{The compliance of functional exercise after modified radical mastectomy in breast cancer patients}

This study showed that the overall functional exercise compliance was $46.16 \pm 3.87$ points in patients with breast cancer after radical mastectomy exercise compliance, which needed to be further improved. The compliance of breast cancer patients with overall functional exercise was poor, especially physical exercise compliance. This outcome may result from the fact that patients were busy with work and life, giving up physical exercise. In fact, as long as patients pay a little attention to affect the recovery of limb behavior in daily life, they can complete the physical exercise. With the facilitation of communication, patients can interact with the medical staff through Tencent instant chat tool, Web Chat, and other forms of Internet. As a result, the initiative by patients to seek advice regarding compliance was high.

\section{Correlation between patient's $\mathrm{HL}$ and functional exercise compliance}

$\mathrm{HL}$ of patients has a direct predictive effect on their therapeutic compliance. Kim et al ${ }^{15}$ critically appraised empirical evidence investigating pathways between HL and cervical

Table 5 Logistic regression analysis of the total score of postoperative functional exercise compliance of breast cancer patients and factors influencing $\mathrm{HL}$

\begin{tabular}{|c|c|c|c|c|c|}
\hline \multirow[t]{2}{*}{ Dimension type } & \multirow[t]{2}{*}{ B } & \multirow[t]{2}{*}{$t$} & \multirow[t]{2}{*}{ Sig } & \multicolumn{2}{|c|}{ EXP(B) $95 \% \mathrm{Cl}$} \\
\hline & & & & Lower limit & Upper limit \\
\hline Information acquisition ability & 0.122 & 3.842 & $0.000^{*}$ & 0.060 & 0.185 \\
\hline Ability to communicate and interact & 0.097 & 1.922 & $0.000^{*}$ & -0.002 & 0.196 \\
\hline Willingness to improve health & 0.858 & 7.694 & 0.056 & 0.638 & $\mathrm{I} .077$ \\
\hline Economic support will & 0.894 & 6.483 & $0.000 *$ & 0.623 & 1.166 \\
\hline
\end{tabular}

Note: $* P<0.05$

Abbreviations: $\mathrm{Cl}$, confidence interval; $\mathrm{HL}$, health literacy; Sig, significance; EXP, exponential. 
cancer screening and reported that evidence supported a positive link between HL and cervical cancer screening. Komenaka et $\mathrm{al}^{16}$ investigated the relationship of HL and screening mammography. A total of 1,664 consecutive patients aged $\geq 40$ years were seen. Only 516 (31\%) patients had undergone screening mammography. Logistic regression analysis that included ethnicity, language, education, smoking status, insurance status, employment, income, and family history found that only three factors were associated with not obtaining a mammogram: low HL, smoking, and being uninsured. In the present study, it was found that the HL of patients could positively predict their functional exercise compliance. Our result showed that HL had a strong association with functional exercise compliance in each dimension except for economic support will and proactively seeking advice compliance (Table 3 ). Patients with high levels of HL have a better understanding of the function of the medical staff and a strong desire to speed up their rehabilitation.

\section{Limitations}

Due to the limitation of objective conditions and research time, this study adopted the convenience sampling method, and only one hospital participated, which may affect the sample representation. Therefore, future studies should increase the representative of the sample and further expand the sample size.

\section{Conclusion}

HL and functional exercise compliance of breast cancer after radical mastectomy in our hospital were both at a moderate level and needed further improvement. HL could predict the functional exercise compliance of patients.

\section{Acknowledgments}

The authors thank all the teachers at their department for supporting this study, including Muhong Guo, Jin Chen, Jin Xu, and Guozhu Wang. Weiwei Tang and Zhouxiao Li share the first authorship.

\section{Disclosure}

The authors report no conflicts of interest in this work.

\section{References}

1. Torre LA, Bray F, Siegel RL, Ferlay J, Lortet-Tieulent J, Jemal. Global cancer statistics, 2012. CA Cancer J Clin. 2015;65(2):87-108.

2. Golubnitschaja O, Debald M, Yeghiazaryan K, et al. Breast cancer epidemic in the early twenty-first century: evaluation of risk factors, cumulative questionnaires and recommendations for preventive measures. Tumour Biol. 2016;37(10):12941-12957.

3. McVeigh TP, Boland MR, Lowery AJ. The impact of the Biomolecular Era on breast cancer surgery. Surgeon. Epub 2016 Nov 1. pii:S1479666X(16)30082-8.

4. Nowicki A, Licznerska B, Rhone P. Evaluation of the quality of life of women treated due to breast cancer using amputation or breast conserving surgery in the early postoperative period. Polish J Surg. 2015; 87(4):174-180.

5. McGuire R, Waltman N, Zimmerman L. Intervention components promoting adherence to strength training exercise in breast cancer survivors with bone loss. West J Nurs Res. 2011;33(5):671-689.

6. Simonds SK. Health education as social policy. Health Educ Monographs. 1974;2:1-10.

7. Kickbusch I, Nutbeam D. Health Promotion Glossary. Geneva: World Health Organization; 1998.

8. Husson O, Mols F, Fransen MP, van de Poll-Franse LV, Ezendam NP. Low subjective health literacy is associated with adverse health behaviors and worse health-related quality of life among colorectal cancer survivors: results from the profiles registry. Psychooncology. 2015;24(4):478-486.

9. Rust CF, Davis C, Moore MR. Medication adherence skills training for African-American breast cancer survivors: the effects on health literacy, medication adherence, and self-efficacy. Soc Work Health Care. 2015; 54(1):33-46.

10. Jin H, Kim Y, Rhie SJ. Factors affecting medication adherence in elderly people. Patient Prefer Adherence. 2016;10:2117-2125.

11. Sun HL. Development and Preliminary Application of Scale on Health Literacy for Patients with Chronic Disease. Fudan University. 2012; 19(3):323-326.

12. Brewer NT, Tzeng JP, Lillie SE, Edwards AS, Peppercorn JM, Rimer BK. Health literacy and cancer risk perception: implications for genomic risk communication. Med Decis Making. 2009;29(2):157-166.

13. Von Wagner C, Steptoe A, Wolf MS, Wardle J. Health literacy and health actions: a review and a framework from health psychology. Health Educ Behav. 2009;36(5):860-877.

14. Smith SK, Petrak LM, Dhillon HM, Taylor J, Milross CG. Are radiation oncologists aware of health literacy among people with cancer treated with radiotherapy? Eur J Cancer Care (Engl). 2014;23(1):111-120.

15. Kim K, Han HR. Potential links between health literacy and cervical cancer screening behaviors: a systematic review. Psychooncology. 2016;25(2):122-130.

16. Komenaka IK, Nodora JN, Hsu CH, et al. Association of health literacy with adherence to screening mammography guidelines. Obstet Gynecol. 2015;125(4):852-859.
Patient Preference and Adherence

\section{Publish your work in this journal}

Patient Preference and Adherence is an international, peer-reviewed, open access journal that focuses on the growing importance of patient preference and adherence throughout the therapeutic continuum. Patient satisfaction, acceptability, quality of life, compliance, persistence and their role in developing new therapeutic modalities and compounds to optimize

\section{Dovepress}

clinical outcomes for existing disease states are major areas of interest for the journal. This journal has been accepted for indexing on PubMed Central. The manuscript management system is completely online and includes a very quick and fair peer-review system, which is all easy to use. Visit http://www. dovepress.com/testimonials.php to read real quotes from published authors. 